\title{
Retraction Note to: The Association Between Modic Changes of Lumbar Endplates and Spontaneous Absorption of Herniated Intervertebral Discs
}

\author{
Lingzhi Ding ${ }^{1} \cdot$ Xiao Teng $^{1} \cdot$ Shunwu Fan ${ }^{2} \cdot$ Fengdong Zhao ${ }^{2}$
}

Published online: 15 April 2020

(c) Springer Science+Business Media, LLC, part of Springer Nature 2020

\section{Retraction Note to: Cell Biochem Biophys (2015) 71:}

1357-1363

https://doi.org/10.1007/s12013-014-0357-y

This article [1] has been retracted by the authors. Dr Shunwu Fan and Dr Fengdong Zhao who own the data, were not aware of the submission of the article and did not agree to its publication.

All authors agree to this retraction.

The original article can be found online at https://doi.org/10.1007/ s12013-014-0357-y.

Lingzhi Ding

dinglingzhi2013@163.com

1 Department of Orthopedics, Taizhou Central Hospital, 999 Donghai Avenue, Taizhou 318000, China

2 Sir Run Run Shaw Hospital, School of Medicine, Zhejiang University, Hangzhou 310016, China

\section{Reference}

1. Ding, L., Teng, X., Fan, S., \& Zhao, F. (2015). The association between modic changes of lumbar endplates and spontaneous absorption of herniated intervertebral discs. Cell Biochemistry and Biophysics, 71, 1357-1363. 